Vol 4 No 2 (2021) 140-148 P-ISSN 2620-295 E-ISSN 2747-0490 DOI: $1047467 /$ elmal.v4i2.530

\title{
Analisis Manajemen Pengelolaan dan Pengembangan Wakaf Produktif di Pondok Pesantren Darussalam Ciomas Bogor
}

\author{
Maulana Irvan Azhari' ${ }^{1}$ Hendri Tanjung2, Yono $^{3}$ \\ 1,2,3Universitas Ibnu Khaldun Bogor \\ azhariirvan05@gmail.com¹, hendri.tanjung@uika-bogor.ac.id². \\ yono@fai.uika-bogor.ac.id ${ }^{3}$
}

\begin{abstract}
Discussed about how research management and development waqf productive in Islamic boarding school darussalam bogor ciomas this study in use of kualittatif in descriptive where made Islamic boarding school darussalam bogor ciomas ciomas as a research.Research show that Islamic boarding school darussalam ciomas bogor of west java in management and use the waqf productive manjerial arise by using basic management for management waqf productive development and do with some effort of them are development through istibdal, coordination with third party, development through purchase assets from the wakif and development through the provision of new wakif assets..
\end{abstract}

Keywords: Management. Research,development, waqf productive and islamic boarding school.

\begin{abstract}
ABSTRAK
Penelitian ini membahas tentang bagaimana manajemen pengelolaan dan pengembangan wakaf produktif di Pondok Pesantren Darussalam Ciomas Bogor penelitian ini menggunakan metode kualittatif yang dipaparkan secara deskriptif dimana menjadikan Pondok Pesantren Darussalam Ciomas Bogor Sebagai Obyek Penelitian. Hasil penelitian menunjukan Bahwasanya Pondok Pesantren Darussalam Ciomas Bogor dalam manajemen pengelolaan wakaf produktif menggunakan sistem manjerial dan swakelola dengan menetapkan manajemen dasar sebagai acuan dan melakukan manajemen pengembangan wakaf produktif dengan beberapa upaya diantaranya adalah pengembangan melalui istibdal, kerjasama dengan pihak ketiga, pengembangan aset melalui pembelian dari hasil wakif dan pengembangan aset melalui pemberian wakif baru.
\end{abstract}

Kata Kunci: Manajemen, pengelolaan, pengembangan, wakaf produktif dan pondok pesantren.

\section{PENDAHULUAN}

Krisis ekonomi yang melanda bangsa Indonesia menyebabkan peningkatan volume kemiskinan masyarakat. Jumlah kemiskinan yang bertambah dari waktu ke 


\section{Vol 4 No 2 (2021) 140-148 P-ISSN 2620-295 E-ISSN 2747-0490 DOI: $1047467 /$ elmal.v4i2.530}

waktu disebabkan karena terpuruknya kondisi ekonomi nasional yang masih terjadi hingga saat ini. Salah satu usaha untuk meningkaktkan kesejahteraan ekonomi masyarakat adalah dengan mengoptimalkan potensi lembaga-lembaga yang telah diatur oleh ajaran Islam seperti zakat, infak, shadaqah, hibah, dan wakaf. Lemagalembaga yang telah ditawarkan oleh pemerintah merupakan satu bentuk dalam mengatasi problematika kehidupan masyrakat khususnya dalam mengatasi kemiskinan. Wakaf sendiri salah satu lembaga yang memiliki potensi tinggi dalam mengatasi dan memberikan jawaban yang nyata ditengah problematika kehidupan masyrakat, khususnya dibidang ekonomi.

Namun kekayaan wakaf yang dimiliki Indonesia, pada umumnya hanya digunakan untuk kepentingan konsumtif saja dan belum dapat dikelola secara produktif. Semua ini disebabkan karena kurangnya pemahaman umat muslim dalam memahami fungsi dan manfaat wakaf itu sendiri dan nazhir yang melakukan pengelolaan dan pengembangan masih belum memahami sepenuhnya. padahal wakaf diperuntukan sebgai aset umat yang pemanfaatannya dapat digunakan sepanjang masa. Dikarenakan manajemen pengelolaan dan pengembangan wakaf di Indonesia masih tertinggal jauh oleh negara Islam lainnya, menyebabkan kurang efektifnya kegunaan wakaf itu sendiri. Hal ini disebabkan pembelajaran wakaf di Indonesia yang masih kurang, sehingga kegiatan wakaf di Indonesia seringkali hanya digunakan untuk keperluan ibadah, seperti masjid, mushola, makam, dll, namun untuk tujuan pemberdayaan, seperti pemberdayaan ekonomi wakaf dan kesejahteraan masih diremehkan. Selain itu, Wakif sendiri hanya memberi tanah atau bangunan, tetapi mereka tidak mau tahu biaya operasional pengelolaan dan pengembangan ekonomi. Disisi lain, orang yang diberi wewenang untuk mengelola wakaf (nadzir) tidak memiliki kemampuan yang baik dalam melakukan manajemen pengelolaan dan pengembangan wakaf, sehingga mereka tidak mampu memanfaatkan wakaf dengan sebaik-baiknya untuk kepentingan masyarakat dan kehidupan. Oleh karena itu, wakaf tidak terorganisir dengan baik dan tidak mampu menyentuh kepentingan masyarakat.

Padahal manajemen pengelolaan dan pengembangan wakaf secara produktif dan profesional oleh nazhir sangatlah penting. Meskipun dalam kitab-kitab fiqih tidak menyebutkan nazhir sebagai salah satu rukun wakaf, karena wakaf sendiri ibadah tabarru. Namun dilihat dari beberapa perspektif dan dilihat dari tujuan wakaf yang ingin mengembangkan manfaat dari hasil harta wakaf, maka keberadaan nazhir sangat dibutuhkan, bahkan nazhir menempati peran sentral. Sebab dipundak nazhirlah tanggung jawab dalam pengelolaan dan mengembangkan wakaf serta menyalurkan hasil atau manfaat dari wakaf tersebut.

\section{Penelitian Terdahulu}

Penelitian yang dilakukan oleh Machmudah (2015) "Manajemen Wakaf Produktif (Studi Perbandingan Di Desa PoncorejoDan Desa Pancangrejo Kecamatan Gemuh Kabupaten Kendal" menununjukan bahwasanya kurangnya sumber daya 


\section{Vol 4 No 2 (2021) 140-148 P-ISSN 2620-295 E-ISSN 2747-0490 DOI: $1047467 /$ elmal.v4i2.530}

manusia dan pengetahuan nazhir mengenai manajemen wakaf sehingga menyebabkan kurang maksimalnya dalam pengelolaan wakaf produktif.

Penelitian yang dilakukan oleh Roni Zulmeisa (2016) tentang "Analisis Pengelolaan Wakaf Produktif Rumah Sewa (Studi Kasus Pada Masjid Al-Furqan Gampang Beurawe Banda Aceh)" sistem pemilihin nazhir yang ada didaerah Rumah sewa pada masjid al-furqon hanya berdasarkan kepercayaan bukan kemampuan nzhir yang profesional sehingga menyebabkan manajemen operasional pengelolaan harta wakaf pada rumah sewa masjid al-furqon masih sederhana. Meskipun secara rukun islam manajemen pengelolaan dan pengembangan wakaf sudah sesuai dengan hukum Islam. Dikarenaka fungsi, tujuan dan peruntukan tidak menyalahi konsep dalam pengelolaan wakaf. Akan tetapi dalam pelaksanaannya masih belum sempurna. Akan tetapi dalam pelaksanaannya masih belum sempurna, seperti manajemen pengelolaan wakaf pada Masjid al-Furqan gampong Beurawe belum memiliki konsep manajemen akad perjanjian yang jelas, nazhir belum melakukan manajemen pengelolaan wakaf rumah sewa yang profesional dan produktif, sehingga potensi wakaf rumah sewa belum dapat dimanfaatkan secara maksimal.

Penelitian yang dilakukan oleh Nur (2017) tentang "Pengelolaan Wakaf Produktif Di Pondok Pesantren Walisongo Ngabar Ponorogo Perspektif UndangUndang Nomor 41 Tahun 2004 Dan Fiqh Empat Mazhab" bahwa pengelolaan wakaf harta wakaf produktif di pondok pesantren walisongo ngabar dikelola oleh YPPWPPWS. Pengelolaan wakaf produktif dengan memproduktifkan sumber atau aset yang ada dengan cara mengelola beberapa unit usaha. Sumber atau aset wakaf dikelola dengan sangat produkif yang kemudia hasil dari penngellaan wakaf dimanfaaatkan untuk memenuhi kebutuhan internal pendidikan, untuk sarana ibadah, menambah invesntaris berupa pembelian tanah baru dan pemberdayaan masyarakat.

\section{Tujuan Penelitian}

Tujuan dari penelitian ini adalah untuk menganalisa bagaimana manajemen pengelolaan dan pengembangan wakaf produktif yang dilakukan di Pondok Pesantren Darussalam Ciomas Bogor. 


\section{Vol 4 No 2 (2021) 140-148 P-ISSN 2620-295 E-ISSN 2747-0490 DOI: $1047467 /$ elmal.v4i2.530}

\section{METODE PENELITIAN}

Peneltian ini termasuk penelitian lapangan (Field Research) yaitu suatu penelitian masyarakat. Yang mana dalam penelitian kualitatif adalah penelitian yang bertujuan untuk memahami kondisi suatu konteks dengan mengarahkan pada pendeskripsian secara rinci dan mendalam mengenai potret kondisi dalam suatu konteks yang alami, tentang apa yang sebenarnya terjadi menurut apa adanya dilapangan (Nugrahani, 2014).

Studi ini menggunakan deskriptif analisa, yang dimana memaparkan teroriteori yang berkaitan dengan manajemen pengelolaan dan pengembangan wakaf khususnya wakaf produktif, baik yang terdapat dalam pembahasan terdahulu, jurnal artikel ataupun sumber-sumber lain yang dipercaya. Adapun pendekatan penelitian yang digunakan oleh penulis adalah metode kualitatif deskriptif. Metode kualitatif deskriptif adalah penelitian yang menekankan catatan dengan deskripsi kalimat yang rinci, lengkap, mendalam yang menggambarkan situasi yang sebenarnya guna mendukung penyajian data (Nugrahani, 2014).

Data yang digunakan dalam penelitian ini menggunakan data primer dan data sekunder. Data primer yaitu data yang belum tersedia dan untuk memperoleh data tersebut peneliti harus menggunakan beberapa instrument penelitian dan istrument yang digunakan dalam penelitian ini dari data primer yaitu wawancara dengan narasumber. Data sekunder yaitu data yang diperoleh dari buku atau artikel jurnal yang diterbitkan oleh lembaga-lembaga baik berupa bahan-bahan bacaan maupun data angka yang ada hubungannya dengan masalah yang diteliti (Tanjung dan Devi, 2018). Guna mendapatkan data yang akurat dan dapat dipertanggung jawabkan kebenaran ilmiahnya, maka peneliti menggunakan teknik pengumpulan data berupa observasi, wawancara dan dokumentasi. Analisis data dimulai dengan melakukan wawancara mendalam dengan informan. Setelah melakukan wawancara, peneliti membuat transkip hasil wawancara dengan cara memutar kembali rekaman wawancara kemudian menuliskan kata-kata yang sesuai dengan apa yang ada direkaman tersebut. Setelah peneliti menulis hasil wawancara kedalam transkip, selanjutnya peneliti membuat reduksi data dengan cara abstraksi, yaitu mengambil data yang sesuai dengan konteks penelitian dan mengabaikan data yang tidak diperlukan (Prabowo dan Heriyanto, 2015).

Penelitian ini dilakukan di Pondok Pesantren Darussalam Ciomas Bogor secara offline dengan bersama praktisi wakaf di Pondok Pesantren Darussalam Ciomas Bogor pada tanggal 10 Maret 2021 dengan Deden Al-Hikmatullah selaku dewan pengelolaan dan pengembangan wakaf Pondok Pesantren Darussalam Ciomas Bogor Jl. Sawah Baru Utama RT. 01/RW.02, Padasuka, Ciomas, Bogor, Jawa Barat.

\section{HASIL ANALISIS DAN PEMBAHASAN}




\section{Vol 4 No 2 (2021) 140-148 P-ISSN 2620-295 E-ISSN 2747-0490 DOI: $1047467 /$ elmal.v4i2.530}

Dalam perwakafan, pengelola wakaf atau nazhir sangat membutuhkan manajemen dalam menjalankan tugasnya. Manajemen ini digunakan untuk mengatur kegiatan pengelolaan wakaf, menghimpun dana dan mendistribusikan hasil wakaf, dan menjaga hubungan baik antara nazhir , wakif dan masyarakat (Rozalinda, 2015). manajemen dalam islam adalah suatu pengelolaan yang mengatur organisasi untuk memperoleh hasil yang optimal dan bermuara pada pencarian keridhaan Allah, artinya setiap kegiatan yang dikerjakan bertujuan untuk mendapatkan keridhaan serta keberkahan dari Allah SWT (Herzeqovina, 2020). Manajemen syari'ah sendiri membahas mengenai perilaku yang terkait dengan nilainilai keimanan dan ketauhidan berbeda dengan manajemen konvensional yang sama sekali tidak berkait dengan bahkan terlepas dari nilai tauhid itu sendiri. Manajemen syari'ah juga membahas mengenai organisasi atau struktur, yang merupakan sunnatullah dan struktur yang berbeda atau tingkatan yang berbeda merupakan ujian yang diberikan Allah Swt manajemen sayriah juga membahas mengenai sistem, dimana sistem yang dibuat harus menyebabkan perilaku pelakunya berjalan dengan baik (Hafidhuddin \& Tanjung, 2008)

Dalam mengelola harta wakaf produktif . perlu adanya manajemen yang mengelola asset wakaf secara transparan dan akuntabel, model manajemen ini bisa dijabarkan dalam beberapa hal berikut :

a. Kepengurusan wakaf terdiri dari nadzir dan dewan pengurus yang pembentukannya sesuai kondisi.

b. Wakif hendaknya menentukan nadzir dan honor atas kerjanya.

c. Kepengurusan wakaf memerlukan dewan pengurus dalam kondisi apabila wakif belum menentukan nazhir dan cara pemilihannya.

Dalam penelitian ini responden merupakan dewan pengelolaan dan pengembangan wakaf pondok pesantren yang mengetahui seberapa kesesuaian konsep wakaf produktif yang telah berjalan. Sesuai dengan konsep wakaf produktif menurut antonio yang dikutip oleh (zainal, 2017) dimana pemberdayaan wakaf wakaf memiliki tiga ciri utama, yaitu : pola manjemen wakaf yang terintegrasi, asas kesejahteraan nazhir dan asas transformasi dan tanggung jawab, kali ini peneliti akan membahas mengenai manajemen pengelolaan dan pengembangan wakaf produktif yang ada di Pondok Pesantren Darussalam Bogor

\section{Manajemen Pengelolaan Wakaf Produktif di Pondok Pesantren Darussalam Ciomas Bogor}

Berkaitan dengan manjemen pengelolaan wakaf produktif, Pondok Pesantren Darussalam Ciomas Bogor dalam manajemen pengelolaannya menggunakan sistem manajerial dan swakeloa dimana setiap unit usaha di pilih atau dipimpin oleh guru yang bertindak sebagai manajer atau nadzir atau pengelola.. Jadi nadzir atau manajer dipilih berdasarkan kesepakatan pihak-pihak yang ada pada saat akad wakaf berlangsung. Meskipun ada beberapa unsur manajerian yang belum dipenuhi dalam pemilihan nadzir atau manajer namun tata cara pelaksanaan wakaf sudah sesuai dengan syari'at islam. Hal ini ditujukan untuk pendidikan daripada profesionalisme 


\section{Vol 4 No 2 (2021) 140-148 P-ISSN 2620-295 E-ISSN 2747-0490 DOI: $1047467 /$ elmal.v4i2.530}

pekerjaan, maka dari itu ukuran standar profesionalisme dalam pekerjaan tidak dapat diterapkan secara utuh di pesantren.

Meskipun dalam sistem manajemen pengelolaan dan pengembangan wakaf produktif masih belum sempurna akan tetapi wakaf hal tersebut sudah memenuhi syari'at islam karena syarat dan rukun nya sudah terpenuhi sedangkan secara perundang-undangan syarat yang telah dijalankan baru 75\%.

Dalam pengelolaan wakaf produktif pondok pesantren telah menerapkan manajemen dasar dalam pelaksanaan pengelolaan dan pengembangan wakaf produktif di antaranya adalah
1. Planning
2. Organization
3. Coordination
4. Contorling
5. Leading
6. Evaluasi.

Dimana Manajemen dasar yang dilakukan merupakan suatu acuan agar segala kegiatan dalam upaya pengelolaan dan pengembangan dapat berjalan secara sistematis, terencana, terstruktur dan terkontrol sehingga mampu mencapai apa yang di tuju atau di inginkan.

\section{Permasalahan dalam Pengelolaan Wakaf Produktif di Pondok Pesantren Darussalam Ciomas Bogor}

Dalam pelaksanaan pengelolaan dan pengembangan wakaf produktif tentunya tidak lepas dari berbagai permasalahan yang dihadapi oleh pengelolaannya. Permasalahan ini tentunya juga dirasakan oleh Pondok Pesantren Darussalam Ciomas Bogor. Meskipun dalam pengelolaan dan pengembangan nya sudah berjalan cukup baik tentu saja masih di temukan beberapa kendala yang menyebabkan pengelolaan wakaf belum mampu berjalan baik diantaranya adalah pertama, minimnya pemahaman masyarakat mengenai wakaf, karena masyarakat masih menganggap wakaf hanya untuk keperluan peribadatan saja padahal wakaf dapat dimanfaatkan lebih dari sekedar tempat ibadah saja. Kedua, minimnya kemampuan nadzir dalam pengelolaan dan pengembanagan wakaf. ketiga kurangnya kesadaran nadzir dalam menjaga benda wakaf, yang mana terkadang benda wakaf di anggap milik pribadi.

ada beberapa upaya yang dilakukan guna meminimalisir permasalahan atau kendala yang ada, diantaranya adalah :

a. Melakukan pembinaan terhadap nadzir, seperti menambah pengetahuan dan wawasan para nadzir wakaf yang ada. Dimana hal ini diharapkan mampu membuat para nadzir menjadi lebih professional, tanggung jawab dan amanah.

b. Memberikan pemahaman dan wawasan kepada masyarkat.bahwasanya kegiatan wakaf bukan hanya untuk kegiatan peribadatan saja. 


\section{Vol 4 No 2 (2021) 140-148 P-ISSN 2620-295 E-ISSN 2747-0490 DOI: $1047467 /$ elmal.v4i2.530}

c. Mebangun lembaga kenadziran sehingga wakaf-wakaf yang ada dapat dikelola secara optimal.

d. Melakukan pembuatan akta wakaf atau sertifikat wakaf.

\section{Manajemen Pengembangan Wakaf Produktif di Pondok Pesantren Darussalam Ciomas Bogor}

Disamping itu dalam upaya pengembangan yang akan datang Pondok Pesantren Darussalam Ciomas Bogor, melakukan beberapa upaya kedepan dalam pengembangannya diantaranya adalah melakukaan pembinaan terhadap nadzir dengan mengikuti beberapa kegiatan pembinaan, pelatihan ataupun mengikut study banding ke beberapa lembaga wakaf yang sudah berkembang di Indonesia seperti Pondok Modern Darussalam Gontor ataupu Universitas Islam Indonesia, mrlakukan pengembangan aset,bekerjasama dengan Badan Wakaf Indonesia, Pembentukan Kemitraan usah, Sosialisasi wakaf produktif, dan penyaluran yang terarah

\section{Manajemen Pengelolaan dan pengembangan Wakaf Produktif di Pondok Pesantren Darussalam Ciomas Bogor}

wakaf produktif yang berada Pondok Pesantren Darussalam Ciomas Bogor tersebut dapat dikatakan berfungsi sebagaimana mestinya dikarenakan beberapa faktor diantaranya adalah : pertama faktor manajemen bahwasanaya faktor ini adalah faktor yang paling utama dalam melakukan pengoperasian wakaf produktif. Faktor ini juga sebagai tolak ukur akan sukses atau tidaknya wakaf produktifi, dalam hal ini pengelola wakaf telah menerapkan sistem manajemen yang baik sehingga sehingga dari tahun ketahun aset wakaf yang dimiliki semakin bertambah Kedua Faktor lokasi, Meskipun menurut sumber wawancara lokasi yang dimiliki Pondok Pesantren Darussalam Ciomas Bogor tidak cukup strategis bagi masyarakat, namaun dengan keadaan aset wakaf yang ada di lingkungan pesantren membuat aset wakaf tetap berjalan dengan baik, dikarenakan aset wakaf yang ada kebutuhan primer bagi para santri. Namun dalam melakukan Manajemen pengelolaan dan pengembangan asset wakaf di Pondok Pesantren Darussalam Ciomas Bogor bukan hanya karena dua faktor melaikan ada beberapa hal yang tentunya telah dicapai melalui beberapa upaya diantaranya adalah :

a. Pengembangan melalui istibdal.

b. Aset melalui kerjasama dengan pihak ketiga.

c. Pengembangan aset melalui pembelian dari hasil wakaf.

d. Pengembangan asett melalui pemberian oleh wakif baru.

\section{KESIMPULAN}

Manajemen pengelolaan wakaf produktif yang dijalankan oleh pondok pesantren Darussalam ciomas Bogor melakukan sistem manajerial dan swakelola, dimana setiap unit usaha di pilih atau dipimpin oleh guru yang bertindak sebagai 


\section{Vol 4 No 2 (2021) 140-148 P-ISSN 2620-295 E-ISSN 2747-0490 DOI: $1047467 /$ elmal.v4i2.530}

manajer atau nadzir atau pengelola. Sistem manajemen yang di jalankan oleh Pondok Pesantren berasas pada unsur-unsur manajemen dasar yakni planning, organization, coordination, controlling, leading dan evaluasi, yang mana sistem manajemen dasar ini sebagai acuan agar segala kegiatan dalam upaya pengelolaan dan pengembangan dapat berjalan secara sistematis, terencana, terstruktur dan terkontrol sehingga mampu mencapai apa yang di tuju atau di inginkan. Manajemen pengembangan wakaf produktif yang dilakukan oleh Pondok Pesantren Darussalam Ciomas Bogor telah dilakukan dengan beberapa upaya seperti pengembagan melalui istibdal,, penamabahan aset melalui kerjasama dengan pihak ketiga, pengembangan aset melalui pembelian dari hasil wakaf dan pengembangan aset melalui pemberian oleh wakif baru. Meskipun pengembangan yang dilakukan telah berjalan cukup baik namun upaya yang dilakukan tidak cukup sampai disitu pengelola wakaf berniat untuk mengembangkan wakaf menjadi lebih maju kedepannya dengan melakukan beberapa hal seperti upaya peningkatan standarisasi mutu kerja nadzir, pengembangan aset wakaf produktif, berkoordinasi atau bekerjasama dengan Badan Wakaf Indonesia, sosialisai wakaf, dan penyaluran hasil wakaf yang terarah.

\section{DAFTAR PUSTAKA}

Hafidhuddin, D. \& Tanjung, H. (2008). Manajemen Syari'ah dalam Praktik. Jakarta : Gema Insani.

Hasil wawancara Analisis Manajemen Pengelolaan dan Pengembangan Wakaf Produktif di Pondok Pesantren Darussalam Ciomas Bogor dengan Deden AlHikmatullah ( Dewan Pengelolaan dan Pengembangan wakaf) 10 Maret 2021, Rabu, Pukul 09:30 WIB

Herzeqovina, B. (2020). Konsep Manajemen Bisnis Islam Dalam Pandangan Islam Berdasarkan Al-Qur'an dan Hadits. Al-Fatih : Jurnal Pendidikan dan Keislaman, 3(1), 143.

Nugrahani, F. (2014). Metode Penelitian Kualitatif. Solo : Cakra Books.

Prabowo. \& Heriyanto. (2013). Analisis pemanfaatan buku elektronik. Ilmu Perpustakaan, 2(2), 152-161.

Tanjung, H. \& Devi, A. (2018). Metodologi Penelitian Ekonomi Islam. Bekasi : Gramata Publishing.

Zainal, V.R. \& Lupitasari, C.I. (2017). Model Pengelolaan Wakaf Produktif di Pondok Modern Darussalam Gontor dan Perannya Terhadap Pengembangan Universitas Darussalam Gontor. Al-Awqaf: Jurnal Wakaf dan Ekonomi Islam, 10(1), 69. 
Cl, IVITIV I Jurnal Kajian Ekonomi \& Bisnis Islam

Vol 4 No 2 (2021) 140-148 P-ISSN 2620-295 E-ISSN 2747-0490 DOI: $1047467 /$ elmal.v4i2.530 